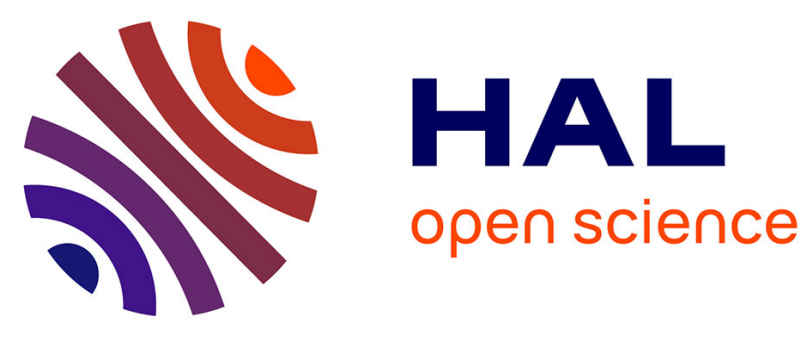

\title{
Synchronous Metastatic Clear-Cell Renal Cell Carcinoma: A Distinct Morphologic, Immunohistochemical, and Molecular Phenotype
}

Solène-Florence Kammerer-Jacquet, Angélique Brunot, Adélaide Pladys, Guillaume Bouzille, Julien Dagher, Sarah Médane, Benoit Peyronnet, Romain Mathieu, Grégory Verhoest, Karim Bensalah, et al.

\section{To cite this version:}

Solène-Florence Kammerer-Jacquet, Angélique Brunot, Adélaide Pladys, Guillaume Bouzille, Julien Dagher, et al.. Synchronous Metastatic Clear-Cell Renal Cell Carcinoma: A Distinct Morphologic, Immunohistochemical, and Molecular Phenotype. Clinical Genitourinary Cancer, 2017, 15 (1), pp.e1e7. 10.1016/j.clgc.2016.06.007 . hal-01470708

\section{HAL Id: hal-01470708 \\ https://hal-univ-rennes1.archives-ouvertes.fr/hal-01470708}

Submitted on 13 Dec 2018

HAL is a multi-disciplinary open access archive for the deposit and dissemination of scientific research documents, whether they are published or not. The documents may come from teaching and research institutions in France or abroad, or from public or private research centers.
L'archive ouverte pluridisciplinaire HAL, est destinée au dépôt et à la diffusion de documents scientifiques de niveau recherche, publiés ou non, émanant des établissements d'enseignement et de recherche français ou étrangers, des laboratoires publics ou privés. 
2

\section{TITLE PAGE}

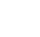

Synchronous metastatic clear cell renal cell carcinoma: a distinct morphological, immunohistochemical and molecular phenotype

\section{Short title: Synchronous metastatic renal cell carcinoma}

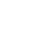

Solene-Florence Kammerer-Jacquet, $\mathrm{MD}^{1,2}$, Angelique Brunot, $\mathrm{MBBS}^{3}$, Adelaide Pladys ${ }^{4}$,

Guillaume Bouzille, $\mathrm{MD}^{5}$, Julien Dagher, $\mathrm{MBBS}^{1}$, Sarah Medane, MBBS${ }^{2}$, Benoit Peyronnet, $\mathrm{MD}^{7}$, Romain Mathieu, $\mathrm{MD}, \mathrm{PhD}^{7}$, Gregory Verhoest, $\mathrm{MD}, \mathrm{PhD}^{7}$, Karim Bensalah, $\mathrm{MD}$, $\mathrm{PhD}^{7}$, Julien Edeline, $\mathrm{MD}^{3}$, Brigitte Laguerre, $\mathrm{MD}^{3}$, Alexandra Lespagnol, $\mathrm{PhD}^{6}$, Jean Mosser, PharmD, $\mathrm{PhD}^{6}$, Frederic Dugay, PharmD, $\mathrm{PhD}^{8}$, Marc-Antoine Belaud-Rotureau, PharmD, $\mathrm{PhD}^{2,8}$ and Nathalie Rioux-Leclercq, $\mathrm{MD}, \mathrm{PhD}^{1,2}$

1- Department of Pathology, Unversity Hospital, 35000 Rennes, France 2- CNRS, UMR 6290 (IGDR), Rennes 1 University, 35000 Rennes, France

3- Department of Medical Oncology, CRLCC, 35000 Rennes, France

4- Department of Epidemiology, EHESP, 35000 Rennes, France

5- Department of Clinical Investigation, Unversity Hospital, 35000 Rennes, France

6- Department of Molecular Genetics, Unversity Hospital, 35000 Rennes, France

7- Department of Urology, Unversity Hospital, 35000 Rennes, France

8- Cytogenetic and Cellular Biology Laboratory, Unversity Hospital, 35000 Rennes, France 
26 Corresponding author:

27 Solene-Florence Kammerer-Jacquet

28 Service d'Anatomie Pathologique

29 CHU Pontchaillou

$30 \quad 2$ rue Henri Le Guilloux

3135033 Rennes Cedex 9, France

32 Telephone number: 0033299284279

33 Fax number: 0033299284284

34

35

36

37

38

39

40

41

42

43

44

45

46

47

48

Word count of text: 3754 words

49

Word count of the abstract: 249 words

50 


\section{ABSTRACT}

\section{Micro abstract}

In order to compare synchronous and metachronous metastatic clear cell renal cell carcinoma (ccRCC), we performed a pathological, immunohistochemical and molecular study on primary tumors in a retrospective series of 48 consecutive patients with up to ten years of follow-up. Synchronous metastatic ccRCC had a distinct phenotype that may explain their worse prognosis.

Introduction: Clear cell renal cell carcinomas (ccRCC) are highly metastatic tumors with metastases detected at diagnosis (synchronous) or during follow-up (metachronous). To date, there have been no reports comparing primary ccRCC of synchronous and metachronous metastatic patients, yet different in terms of prognosis. Determining whether there is a phenotypic difference between these two groups could have important clinical implications. Patients and Methods: In a retrospective consecutive cohort of 98 patients with ccRCC, 48 patients had metastases including 28 synchronous and 20 metachronous presentations with a follow-up of 10 years. For each primary tumor in these metastatic patients, pathological criteria, expression of VEGF, PAR-3, CAIX and PD-L1 as detected by immunohistochemistry, and complete VHL status were analyzed. Univariate analysis was performed and survival was assessed using Kaplan-Meier curves compared by log-rank test.

Results: Compared to primary ccRCC in metachronous metastatic patients, primary ccRCC in synchronous metastatic patients were significantly associated with a poorer ECOG performance $(\mathrm{p}=0.045)$, higher $\mathrm{pT}$ status $(\mathrm{p}=0.038)$, non-inactivated $V H L$ gene $(\mathrm{p}=0.01)$, sarcomatoid component ( $\mathrm{p}=0.007)$, expression of PAR-3 $(\mathrm{p}=0.007)$, and overexpressions of VEGF $(>50 \%)(p=0.017)$ and PD-L1 ( $\mathrm{p}=0.019)$. Patients with synchronous metastases had a 
76 worse cancer-specific survival than patients with metachronous metastases even from

77 metastatic diagnosis (median survival 16 months versus 46 months, respectively, $\mathrm{p}=0.01$ ).

78 Conclusion: This long-term study is the first to support the notion that synchronous m-

79 ccRCC has a distinct phenotype. This is probably linked to the occurrence of oncogenic

80 events that could explain their worse prognosis. These particular metastatic patients could

81 benefit from specific therapy.

82

83 Keywords: clear cell renal cell carcinoma; synchronous and metachronous metastases;

84 phenotype; clinical outcome

85

86

87

88

89

90

91

92

93

94

95

96

97

98

99

100 
101

102

103

104

105

106

107

108

109

110

111

112

113

114

115

116

117

118

119

120

121

122

123

124

125

\section{TEXT}

\section{INTRODUCTION}

Clear cell renal cell carcinoma (ccRCC) is the most common histologic subtype of renal cell carcinoma. ${ }^{1}$ Tumor cells are characterized by inactivation of the VHL gene leading to HIF stabilization, which induces the transcription of genes such as vascular endothelial growth factor $(V E G F){ }^{2}$ As a consequence, the tumor microenvironment is highly vascularized. Another critical component of the tumor microenvironment is the immune system as some tumors have a high density of tumor infiltrating lymphocytes (TIL). ${ }^{3}$ Moreover, tumor cells were shown to express programmed death ligand 1 (PD-L1) to escape the immune system. ${ }^{4,5}$

With approximately $40 \%$ of patients dying of metastases, ccRCC are highly aggressive tumors. ${ }^{6}$ The most common sites of metastasis are the lungs, distant lymph nodes, liver, bones, brain and adrenal gland. Twenty to $30 \%$ of patients are diagnosed with metastatic disease (synchronous presentation) whereas $20 \%$ of patients with non-metastatic disease at diagnosis will later develop metastases during follow-up (metachronous presentation). ${ }^{7}$ Metastases generally arise in the first six years after surgery. ${ }^{8}$

Synchronous and metachronous ccRCC have a different prognosis. Currently, one of the criteria of MSKCC and Heng risk criteria models for predicting survival in metastatic patients is a time from initial diagnosis (including original localized disease) to treatment of less than one year. ${ }^{9-11}$ This risk factor includes synchronous metastatic patients. The difference in prognosis between the two groups of patients may be linked to their primary tumors having different phenotypes. To our knowledge, there are no reports comparing primary ccRCC in 
synchronous and metachronous metastatic patients. Determining whether there is a phenotypic difference between these two groups could have important clinical implications.

128

129 This is the first study to conduct an in-depth analysis of primary ccRCC in correlation with

130 pathological criteria, VHL status and long-term clinical outcome with a view to seeking

131 differences depending on synchronous or metachronous metastatic status.

132

133

MATERIALS AND METHODS

134

135

Patients

136 Between 2002 and 2005, 98 consecutive patients were operated for sporadic ccRCC in the

137 Department of Urology at Rennes University Hospital. Twenty-eight patients had

138

139

140

141

142

143

144

145

146

147 148

149 synchronous metastases at initial diagnosis and underwent nephrectomy in accordance with international guidelines. ${ }^{12}$ They received no prior therapy. Twenty patients had a nephrectomy before developing metastases which were detected during follow-up (first CT scan 6 months after surgery) and defined as metachronous. Consequently, a total of 48 patients presented metastases between 2002 and 2012 and were included in our study. Patient charts were retrospectively reviewed to assess pretreatment ECOG performance status, methods of detection (incidental or symptomatic), involved metastatic sites with retrieved first staging CT scan, MSKCC score, Heng criteria and therapies ${ }^{9,11}$. The outcome was specific death which we assessed with a 10-year follow-up. The study protocol was approved by the local advisory board and informed consent was obtained from each patient for the study.

\section{Tissue sample management}


150 Tumor samples were obtained from the processing of biological samples by the Rennes

151 Biological Resources Center-Health (CRB-Health) (BB-0033-00056). The research protocol

152 was conducted under French legal guidelines and fulfilled the requirements of the local

153 institutional ethics committee. All consecutive ccRCC and paired renal cortex samples were

154 analyzed. Immediately after macroscopic examination, small samples were collected from

155 surgical specimens, frozen in liquid nitrogen and stored at $-80^{\circ} \mathrm{C}$ until DNA extraction.

156 Genomic DNA was extracted from 25 to $35 \mathrm{mg}$ of frozen tissue sections using a QIAamp

157 DNA minikit (Qiagen, Courtaboeuf, France). DNA quantity and quality were estimated by

158 optical density (OD 260/280) measurement and 0.8\% agarose gel electrophoresis using

159 standard protocols.

160

161 Pathological analysis

162 After fresh tissue sampling, surgical specimens were formalin-fixed. Paraffin sections were

163 stained with hematoxylin and eosin-safran for light microscopy. All slides were reviewed by a

164 dedicated uropathologist (NRL). The macroscopic and histological parameters analyzed were:

165 tumor size, multifocality, nucleolar grade according to the International Society of Urological

166 Pathology (ISUP) grading system, sarcomatoid component, tumor necrosis, granular

167 component, lymphocyte infiltrate and microvessel invasion. ${ }^{13}$ Sarcomatoid component was

168 defined as more than $10 \%$ involvement of the tumor. Tumor stage was defined by the latest

169 International Union Against Cancer classification (2009). ${ }^{14}$

\section{Immunohistochemistry}

172 For each ccRCC case, a representative slide of the tumor with the highest nucleolar grade and

173 the corresponding paraffin block were selected. VEGF (anti-VEGF antibody, sc-152, dilution

174 1/100; Santa Cruz Biotechnology, Santa Cruz, CA, USA), CAIX (anti-CAIX antibody, 
175

176

177

178

179

180

181

182

183

184

185

186

187

188

189

190

191

192

193

194

195

196

197

198

199

ab15086, dilution 1/1500, Abcam, Cambridge, UK), PAR-3 (anti-PAR-3, HPA0300443, dilution 1/50, Sigma-Aldrich, Saint Louis, USA) and PD-L1 (anti-PD-L1 antibody, clone 130021, dilution 1/200, R\&D Systems, Minneapolis, MN, USA) expression was assessed by immunohistochemistry as previously described. ${ }^{15-17}$ The cut-off for positive cases was $85 \%$ of tumor cells for CAIX as described in a previous study. ${ }^{16,18}$ The percentage of tumor cells for VEGF was reported. Only cytoplasmic PAR-3 expression in tumor cells was considered positive. ${ }^{17}$ PD-L1 was overexpressed when intensity of membranous or cytoplasmic staining in tumor cells was moderate to strong as previously described. ${ }^{19}$ Regarding tumor infiltrating lymphocytes, CD3 (anti-CD3 antibody, clone SP7, dilution 1/100; Thermo Scientific, Waltham, MA, USA) and CD20 (anti-CD20 antibody, clone L26, dilution 1/25; Dako, Glostrup, Denmark) expression was assessed. The inflammatory extent was coded as one (few sparse lymphocytes in the tumor) or two (marked dense lymphocytes or lymphoid nodules). IHC scoring was independently assessed by two pathologists (SFKJ and NRL) blinded to the clinical grouping of the specimens. Discordant cases were reevaluated collegially to reach a consensus score.

\section{VHL gene analysis}

We determined the complete VHL status for each tumor by analyzing VHL gene mutation, deletion and promoter methylation. VHL mutations were detected by sequencing using denaturing high-performance liquid chromatography (DHPLC). All mutations were confirmed in a second round of PCR and sequencing reactions. VHL gene deletions and promoter methylation were detected by Multiplex Ligation-dependent Probe Amplification (MLPA) analysis using the SALSA MLPA P016B VHL probe kit and the SALSA MS-MLPA kit, respectively. ${ }^{20}$ As VHL is a tumor-suppressor gene, VHL gene impairments necessarily involve biallelic alterations in tumor cells as two hits are required to be inactivated. Tumors 
with two alterations of the VHL gene were defined as inactivated for that gene (inVHL). Those with no or only one alteration were defined as non-inactivated VHL tumors (niVHL).

\section{Statistical analysis}

$\chi 2$, Fisher's exact and Mann-Whitney tests were performed to compare qualitative and quantitative parameters, respectively between the synchronous and metachronous metastatic patient groups. Cancer-specific survival (CSS) was calculated from metastasis diagnosis to death from cancer. The Kaplan-Meier method was used to represent CSS, and the resulting curves were compared using log-rank tests. All p-values were 2-sided, and p-values less than 0.05 were considered statistically significant. All statistical analyses were performed using Stata 11.1 (College Station, TX, USA) software.

\section{RESULTS}

\section{Patient and tumor characteristics}

The population characteristics and pathological parameters are summarized in Table 1 . The median age at diagnosis was 61 years (42-80). Twenty-three patients (47.9\%) had an ECOG performance status of 0 . The mean tumor size was $9 \mathrm{~cm}$ with tumors ranging from 2 to $18 \mathrm{~cm}$. In 6 cases (12.5\%), nodal invasion was present. Twenty-eight patients (58.3\%) had synchronous metastases at diagnosis whereas 20 patients (41.7\%) developed metastases after initial diagnosis with a 32-month mean (6-78 months). The most common metastatic sites were the lungs in 32 cases (66.7\%), bones in 27 cases (56.3\%), distant lymph nodes in 16 cases (33.3\%) and liver in 7 cases (14.6\%). Less common sites were the brain in three cases (6.3\%), soft tissue in four cases (8.3\%), adrenal gland in five cases (10.4\%), pancreas in two cases (4.1\%), peritoneum in one case (2.1\%), contralateral kidney in two cases (4.1\%) and 
digestive organs in three cases (6.3\%). Several sites were frequently involved in 32 cases (66.6\%) whereas only one site was involved in 16 cases (33.3\%). Before systemic treatment, most patients had intermediate or high risk according to MSKCC or Heng models. When eligible for systemic treatment, the patients received various therapies such as cytokines in 14 cases, sunitinib (first-line or second-line therapy) in 13 cases, sorafenib in two cases, hormone therapy in three cases and standard chemotherapy in two cases. Eleven patients were referred to supportive care specialists and eight patients were not treated in our center. With a followup of 10 years, 43 patients (89.6\%) from our study died of their cancer.

\section{Synchronous and metachronous m-ccRCC: a distinct phenotype}

The synchronous and metachronous metastatic patient and tumor characteristics are summarized and compared in Tables 2 and 3. Synchronous and metachronous m-ccRCC shared the following features: aggressive tumors with symptomatic detection (75\%), a median tumor size of 9cm (2-18 cm), a high nucleolar grade (grade 3-4 in 87.5\%), tumor necrosis (70.8\%), granular component (72.9\%), microvascular invasion (60.4\%) and overexpression of VEGF (79.2\%). However, compared to metachronous m-ccRCC, synchronous m-ccRCC had a poorer ECOG score $(\mathrm{p}=0.045)$, a worse risk group in both MSKCC and Heng models ( $p=0.007$ and $p=0.010$ respectively) and corresponded to even more aggressive tumors with higher $\mathrm{pT}$ status $(\mathrm{p}=0.038)$ and sarcomatoid component $(\mathrm{p}=0.007)$. In the immunohistochemistry analysis, they were associated with overexpression of VEGF with a $50 \%$ cut-off ( $\mathrm{p}=0.017$ ) as defined by a receiver operating characteristic (ROC) curve, expression of PAR-3 ( $\mathrm{p}=0.007)$ and overexpression of PD-L1 ( $\mathrm{p}=0.019)$. At the molecular level, they were associated with a non-inactivated $V H L$ gene $(\mathrm{p}=0.01)$. The pathological and immunohistochemical phenotype of synchronous m-ccRCC is shown in Figure 1. 


\section{Worse clinical outcome with synchronous m-ccRCC}

251 Patients with synchronous metastases had a worse CSS from the date of metastasis diagnosis compared to patients with metachronous metastases without statistical differences between the

253 two groups in care management. They had a median survival of 16 months versus 46 months for the patients with metachronous metastases $(p=0.01)$, Figure 3. Five-year survival was 3.6\% for patients with synchronous metastases and $20 \%$ for patients with metachronous metastases.

\section{DISCUSSION}

To our knowledge, this is the first study to compare synchronous and metachronous primary m-ccRCC. While our results may be seen to be limited in terms of sample size, we present a highly detailed study at the pathological, immunohistochemical and molecular levels in a retrospective series of consecutive ccRCC patients with a long-term clinical follow-up of up to ten years. Due to the period of our study, treatments were quite heterogeneous without statistical difference between the two groups. Besides, patients received no prior systemic therapy before nephrectomy.

Primary ccRCC in both synchronous and metachronous metastatic patients is characterized by aggressive and disseminating tumors. However, we report a distinct pathological and molecular phenotype of the primary tumors. In the m-ccRCC group, synchronous m-ccRCC was particularly associated with a higher pT status, sarcomatoid component, cytoplasmic expression of PAR-3, overexpression of VEGF and PD-L1 and a niVHL gene.

Sarcomatoid ccRCC may represent a completed epithelial-mesenchymal transition (EMT). ${ }^{21}$ Invasion of the basement membrane and extracellular matrix is an essential event in tumor 
275 progression and considered a critical step during metastasis. ${ }^{22}$ Partitioning-defective 3 (PAR-

276 3), a crucial component of partitioning-defective complex proteins, was recently described as

277

278

279

280

281

282

283

284

285

286

287

288

289

290

291

292

293

294

295

296

297

298

299

an independent prognostic factor in ccRCC. ${ }^{17,23}$ It is implicated in the development and maintenance of cell polarity. As it modulates cell-cell communication and promotes collective cell migration, PAR-3 may be involved in cancer cell EMT and metastasis formation in ccRCC. ${ }^{23}$ Angiogenesis is also considered a crucial step in the progression of cancer. VEGF expression is a key molecular mechanism underlying the initiation and maintenance of the entire tumor process. ${ }^{24,25}$ Tumor progression is often paralleled by higher levels of VEGF expression as cancer cells gradually acquire their malignant potential. ${ }^{25}$

Interestingly, PD-L1 and the non-inactivated VHL gene were associated with the primary ccRCC in synchronous metastatic patients. The interaction between PD-1, an inducible inhibitory receptor expressed on lymphocytes and dendritic cells, and PD-L1 ligand, expressed by tumor cells, results in down-regulation of the T-cell response. ${ }^{26} \mathrm{PD}-\mathrm{L} 1$ overexpression may reflect the ability of metastatic tumor cells to evade immune surveillance during migration. VHL gene inactivation is likely considered as an initial event in the ccRCC carcinogenic process. ${ }^{2}$ Non-inactivation of the VHL gene more commonly seen in synchronous m-ccRCC may suggest early involvement of non-dependent VHL pathways such as MAP kinase and PI3K-AKT-mTOR pathways that are also implicated in PD-L1 expression. ${ }^{27-29}$

Compared to primary tumors of synchronous m-ccRCC, metachronous m-ccRCC probably acquire less oncogenic events. During the period between nephrectomy and symptomatic metastasis, initially dormant tumor cells acquire oncogenic events that are not predictable in primary tumors. ${ }^{30}$ This explains the heterogeneity between primary tumors and metastasis 
300

301

302

303

304

305

306

307

308

309

310

311

312

313

314

315

316

317

318

319

320

323

already described. ${ }^{4}$ Our study emphasizes the need to assess metastatic sites rather than the primary tumor to identify predictive biomarkers for targeted therapies.

In our study, we confirmed the poor prognosis of synchronous metastatic patients. ${ }^{9}$ As expected, most of them had time from initial diagnosis to treatment of less than one year that is a risk factor in both MSKCC and Heng models. In a recent publication by Beuselinck et al., synchronous m-ccRCC were particularly linked to poor sunitinib response. ${ }^{31}$ This poor prognosis may rely on advantageous oncogenic events acquired in their primary ccRCC such as PD-L1 expression. If confirmed by further studies, these patients may be good candidates for PD1/PDL1 immunotherapy.

\section{CONCLUSION}

In this long-term study of metastatic patients, we revealed that synchronous m-ccRCC had a distinct phenotype which is likely explained by the occurrence of oncogenic events. Patients with synchronous m-ccRCC have a worse prognosis and could benefit from specific therapy.

Clinical practice points:

- Patients with synchronous metastatic clear cell renal cell carcinoma (ccRCC) are already known to have a worse prognosis than patients with metachronous metastatic cCRCC.

- For the first time, we compared synchronous and metachronous primary tumors at pathological, immunohistochemical and molecular levels and found a different phenotype of synchronous primary ccRCC. 
- Patients with synchronous metastasis overexpressed PD-L1 and may be good candidates for PD1/PDL1 immunotherapy.

\section{ACKNOWLEDGMENTS}

The authors would like to acknowledge the Ligue Contre le Cancer, the CORECT, Rennes

Hospital and the French Institute of Cancer (INCa) for their financial aid.

The authors would also like to thank the Center of Biological Resources of Rennes Hospital

(BB-0033-00056, http://www.crbsante-rennes.com/) for managing patient samples as well as

Pascale Bellaud and Roselyne Viel from the Histopathology platform H2P2-BIOSIT, Faculty of Medicine of Rennes for their technical support.

\section{DISCLOSURE}

The authors of this article have no relevant financial relationships with commercial interests

to disclose and no funding to declare.

\section{REFERENCES:}

1. Murai M, Oya M. Renal cell carcinoma: etiology, incidence and epidemiology. Curr 
7. Ljungberg B, Campbell SC, Choi HY, et al. The epidemiology of renal cell carcinoma. Eur Urol. 2011;60:615-621.

8. Eggener SE, Yossepowitch O, Pettus JA, Snyder ME, Motzer RJ, Russo P. Renal cell carcinoma recurrence after nephrectomy for localized disease: predicting survival from time of recurrence. J Clin Oncol. 2006;24:3101-3106.

9. Heng DY, Xie W, Regan MM, et al. Prognostic factors for overall survival in patients with metastatic renal cell carcinoma treated with vascular endothelial growth factortargeted agents: results from a large, multicenter study. J Clin Oncol. 2009;27:57945799.

10. Motzer RJ, Bacik J, Mazumdar M. Prognostic factors for survival of patients with stage IV renal cell carcinoma: memorial sloan-kettering cancer center experience. Clin Cancer Res. 2004;10:6302S-6303S.

11. Mekhail TM, Abou-Jawde RM, Boumerhi G, et al. Validation and extension of the Memorial Sloan-Kettering prognostic factors model for survival in patients with previously untreated metastatic renal cell carcinoma. J Clin Oncol. 2005;23:832-841.

12. Heng DY, Wells JC, Rini BI, et al. Cytoreductive nephrectomy in patients with synchronous metastases from renal cell carcinoma: results from the International Metastatic Renal Cell Carcinoma Database Consortium. Eur Urol. 2014;66:704-710.

13. Delahunt B, Cheville JC, Martignoni G, et al. The International Society of Urological Pathology (ISUP) grading system for renal cell carcinoma and other prognostic parameters. The American journal of surgical pathology. 2013;37:1490-1504.

14. Printz C. New AJCC cancer staging manual reflects changes in cancer knowledge. Cancer. 2010;116:2-3.

15. Patard JJ, Rioux-Leclercq N, Masson D, et al. Absence of VHL gene alteration and high VEGF expression are associated with tumour aggressiveness and poor survival of renal-cell carcinoma. Br J Cancer. 2009;101:1417-1424.

16. Patard JJ, Fergelot P, Karakiewicz PI, et al. Low CAIX expression and absence of VHL gene mutation are associated with tumor aggressiveness and poor survival of clear cell renal cell carcinoma. International journal of cancer. Journal international du cancer. 2008;123:395-400.

17. Dagher J, Dugay F, Rioux-Leclercq N, et al. Cytoplasmic PAR-3 protein expression is associated with adverse prognostic factors in clear cell renal cell carcinoma and independently impacts survival. Human pathology. 2014;45:1639-1646.

18. Bui MH, Seligson D, Han KR, et al. Carbonic anhydrase IX is an independent predictor of survival in advanced renal clear cell carcinoma: implications for prognosis and therapy. Clin Cancer Res. 2003;9:802-811.

19. Choueiri TK, Figueroa DJ, Fay AP, et al. Correlation of PD-L1 Tumor Expression and Treatment Outcomes in Patients with Renal Cell Carcinoma Receiving Sunitinib or Pazopanib: Results from COMPARZ, a Randomized Controlled Trial. Clin Cancer Res. 2015;21:1071-1077.

20. Jeuken JW, Cornelissen SJ, Vriezen M, et al. MS-MLPA: an attractive alternative laboratory assay for robust, reliable, and semiquantitative detection of MGMT promoter hypermethylation in gliomas. Lab Invest. 2007;87:1055-1065.

21. Bostrom AK, Moller C, Nilsson E, Elfving P, Axelson H, Johansson ME. Sarcomatoid conversion of clear cell renal cell carcinoma in relation to epithelial-to-mesenchymal transition. Human pathology. 2012;43:708-719.

22. Mikami S, Oya M, Mizuno R, Kosaka T, Katsube K, Okada Y. Invasion and metastasis of renal cell carcinoma. Med Mol Morphol. 2014;47:63-67.

23. Dugay F, Le Goff X, Rioux-Leclerq N, et al. Overexpression of the polarity protein PAR-3 in clear cell renal cell carcinoma is associated with poor prognosis. 
International journal of cancer. Journal international du cancer. 2013;134:20512060.

24. Ferrara N, Gerber HP, LeCouter J. The biology of VEGF and its receptors. Nature medicine. 2003;9:669-676.

25. Olsson AK, Dimberg A, Kreuger J, Claesson-Welsh L. VEGF receptor signalling - in control of vascular function. Nat Rev Mol Cell Biol. 2006;7:359-371.

26. Jilaveanu LB, Shuch B, Zito CR, et al. PD-L1 Expression in Clear Cell Renal Cell Carcinoma: An Analysis of Nephrectomy and Sites of Metastases. Journal of Cancer. 2014;5:166-172.

27. Gallego GA, Villaamil VM, Grande E, Cainzos IS, Aparicio LM. Crossing Paths in Human Renal Cell Carcinoma (hRCC). Int J Mol Sci. 2012;13:12710-12733.

28. Atefi M, Avramis E, Lassen A, et al. Effects of MAPK and PI3K pathways on PD-L1 expression in melanoma. Clin Cancer Res. 2014;20:3446-3457.

29. Ritprajak P, Azuma M. Intrinsic and extrinsic control of expression of the immunoregulatory molecule PD-L1 in epithelial cells and squamous cell carcinoma. Oral oncology. 2015;51:221-228.

30. Wuttig D, Baier B, Fuessel S, et al. Gene signatures of pulmonary metastases of renal cell carcinoma reflect the disease-free interval and the number of metastases per patient. International journal of cancer. Journal international du cancer. 2009;125:474-482.

31. Beuselinck B, Job S, Becht E, et al. Molecular Subtypes of Clear Cell Renal Cell Carcinoma Are Associated with Sunitinib Response in the Metastatic Setting. Clin Cancer Res. 2015. 
1 TABLES

2 Table 1. Summary of the clinical and histopathological characteristics of the 48

3 metastatic patients.

\begin{tabular}{|c|c|}
\hline Variables & Number of patients (\%) \\
\hline \multicolumn{2}{|l|}{ Sex } \\
\hline M & 27 (56.3\%) \\
\hline $\mathrm{F}$ & 21 (44.7\%) \\
\hline \multicolumn{2}{|l|}{ ECOG } \\
\hline 0 & 23 (47.9\%) \\
\hline 1 & 25 (52.1\%) \\
\hline Age (years) & $61(42-80)$ \\
\hline \multicolumn{2}{|l|}{ Mode of detection } \\
\hline Incidental & $12(25 \%)$ \\
\hline Symptomatic & 36 (75\%) \\
\hline Tumour size $(\mathrm{cm})$ & $9(2-18)$ \\
\hline \multicolumn{2}{|l|}{ ISUP grade } \\
\hline 2 & $6(12.5 \%)$ \\
\hline 3 & 18 (37.5\%) \\
\hline 4 & 24 (50\%) \\
\hline \multicolumn{2}{|l|}{ Tumour stage (pT) } \\
\hline 1 & 5 (10.4\%) \\
\hline 2 & $11(22.9 \%)$ \\
\hline 3 & 28 (58.3\%) \\
\hline 4 & $4(8.3 \%)$ \\
\hline \multicolumn{2}{|l|}{ Lymph node status (pN) } \\
\hline 0 & 42 (87.5\%) \\
\hline $1-2$ & $6(12.5 \%)$ \\
\hline \multicolumn{2}{|l|}{ Metastasis status (pM) } \\
\hline 0 & $20(41.7 \%)$ \\
\hline 1 & $28(58.3 \%)$ \\
\hline \multicolumn{2}{|l|}{ MSKCC score } \\
\hline Favorable prognosis & 8 (16.7\%) \\
\hline Intermediate prognosis & 27 (56.3\%) \\
\hline Poor prognosis & $13(27.0 \%)$ \\
\hline \multicolumn{2}{|l|}{ Heng criteria } \\
\hline Favorable prognosis & $9(18.7 \%)$ \\
\hline Intermediate prognosis & 19 (39.6\%) \\
\hline Poor prognosis & 20 (41.7\%) \\
\hline
\end{tabular}


5 Table 2. Clinical features and their association with synchronous or metachronous metastatic patients.

\begin{tabular}{|c|c|c|c|}
\hline Variables & $\begin{array}{l}\text { Patients with } \\
\text { synchronous } \\
\text { m-ccRCC }(n=28)\end{array}$ & $\begin{array}{l}\text { Patients with } \\
\text { metachronous } \\
\text { m-ccRCC }(n=20)\end{array}$ & p-value \\
\hline Sex & & & $\mathrm{p}=0.559 \dagger$ \\
\hline Male & 17 (60.7\%) & $10(50 \%)$ & \\
\hline Female & $11(39.3 \%)$ & $10(50 \%)$ & \\
\hline Age & 62 & 59 & $p=0.216+$ \\
\hline ECOG & & & $p=0.045 \dagger$ \\
\hline 0 & $10(35.7 \%)$ & $13(65 \%)$ & \\
\hline 1 & $18(64.3 \%)$ & 7 (35\%) & \\
\hline Mode of detection & & & $\mathrm{p}=0.198 \dagger$ \\
\hline Incidental & 5 (17.9\%) & 7 (35\%) & \\
\hline Symptomatic & $23(82.1 \%)$ & $13(65 \%)$ & \\
\hline \multicolumn{4}{|l|}{ Metastatic localization } \\
\hline Lung & $11(39.3 \%)$ & $5(25 \%)$ & $\mathrm{p}=0.301 \dagger$ \\
\hline Bone & $10(35.7 \%)$ & $11(55 \%)$ & $\mathrm{p}=0.184 \dagger$ \\
\hline Distant lymph node & $18(64.3 \%)$ & $15(75 \%)$ & $\mathrm{p}=0.430 \dagger$ \\
\hline Liver & $25(89.3 \%)$ & $16(80 \%)$ & $\mathrm{p}=0.429 \ddagger$ \\
\hline Unique site & 17 (60.7\%) & $14(70 \%)$ & $\mathrm{p}=0.507 \dagger$ \\
\hline \multicolumn{4}{|l|}{ MSKCC score } \\
\hline Favorable prognosis & $1(3.6 \%)$ & 7 (35\%) & $\mathrm{p}=0.006+$ \\
\hline Intermediate prognosis & $15(53.6 \%)$ & $12(60 \%)$ & $\mathrm{p}=0.658 \dagger$ \\
\hline Poor prognosis & $12(42.8 \%)$ & $1(5 \%)$ & $\mathrm{p}=0.007+$ \\
\hline \multicolumn{4}{|l|}{ Heng criteria } \\
\hline Favorable $\mathrm{p}$ & $1(3.6 \%)$ & $8(40 \%)$ & $\mathrm{p}=0.002 \ddagger$ \\
\hline Poor prognosis & $11(39.3 \%)$ & $8(40 \%)$ & $\mathrm{p}=0.960 \dagger$ \\
\hline Favorable prognosis & $16(57.1 \%)$ & $4(20 \%)$ & $\mathrm{p}=0.010 \dagger$ \\
\hline \multicolumn{4}{|l|}{ Treatment } \\
\hline Cytokines & $8(19.6 \%)$ & $6(30 \%)$ & $\mathrm{p}=0.914 \dagger$ \\
\hline Sunitinib & $5(17.9 \%)$ & $8(40 \%)$ & $\mathrm{p}=0.086 \dagger$ \\
\hline Others & $5(17.9 \%)$ & $3(15 \%)$ & $\mathrm{p}=0.793 \dagger$ \\
\hline Supportive care & $8(19.6 \%)$ & $3(15 \%)$ & $\mathrm{p}=0.473+$ \\
\hline Unknown & $4(14.3 \%)$ & $4(20 \%)$ & $\mathrm{p}=0.703 \ddagger$ \\
\hline
\end{tabular}

$7 \dagger$ Pearson chi2 test, $\ddagger$ Fisher's exact test, § Mann-Whitney test 
Table 3. Histological, immunohistochemical and molecular features and their

11 association with synchronous or metachronous m-ccRCC.

\begin{tabular}{|c|c|c|c|}
\hline Variables & $\begin{array}{l}\text { Patients with } \\
\text { synchronous } \\
\text { m-ccRCC }(n=28)\end{array}$ & $\begin{array}{l}\text { Patients with } \\
\text { metachronous } \\
\text { m-ccRCC }(n=20)\end{array}$ & p-value \\
\hline \multicolumn{4}{|l|}{ Histological criteria } \\
\hline Tumour size (cm) & 8.9 & 9.2 & $\mathrm{p}=0.722 \ddagger$ \\
\hline ISUP nucleolar grade 4 & $18(64.3 \%)$ & $6(30 \%)$ & $\mathrm{p}=\mathbf{0 . 0 1 9} \dagger$ \\
\hline Tumour stage (T3-4) & $22(78.6 \%)$ & $10(50 \%)$ & $p=0.038 \dagger$ \\
\hline Lymph node status (N1-2) & $5(17.9 \%)$ & $1(5 \%)$ & $\mathrm{p}=0.214 \S$ \\
\hline Tumour necrosis & 19 (67.9\%) & $15(75 \%)$ & $\mathrm{p}=0.591 \dagger$ \\
\hline Sarcomatoid component & $15(53.6 \%)$ & $18(90 \%)$ & $\mathbf{p}=\mathbf{0 . 0 0 7} \dagger$ \\
\hline Granular component & $18(64.3 \%)$ & 17 (85\%) & $\mathrm{p}=0.111 \dagger$ \\
\hline Microvascular invasion & 17 (60.7\%) & $12(60 \%)$ & $\mathrm{p}=0.960 \dagger$ \\
\hline Dense lymphocyte infiltrate & $4(14.3 \%)$ & $1(5 \%)$ & $\mathrm{p}=0.385 \ddagger$ \\
\hline \multicolumn{4}{|l|}{ Immunohistochemical study } \\
\hline VEGF $\geq 50 \%$ & $22(78.6 \%)$ & $9(45 \%)$ & $\mathrm{p}=\mathbf{0 . 0 1 7} \dagger$ \\
\hline CAIX $\geq 85 \%$ & $20(71.4 \%)$ & $14(70 \%)$ & $\mathrm{p}=0.915 \dagger$ \\
\hline Cytoplasmic PAR-3 & $23(82.1 \%)$ & $9(45 \%)$ & $\mathrm{p}=\mathbf{0 . 0 0 7} \dagger$ \\
\hline PD-L1 Intensity 2+ 3+ & $21(75 \%)$ & $7(35 \%)$ & $p=0.019 \dagger$ \\
\hline \multicolumn{4}{|l|}{ VHL status } \\
\hline Deletion & $15(53.6 \%)$ & $16(80 \%)$ & $\mathrm{p}=0.059 \dagger$ \\
\hline Mutation & $16(57.2 \%)$ & $16(80 \%)$ & $\mathrm{p}=0.097 \dagger$ \\
\hline Promoter methylation & $2(7.1 \%)$ & $3(15 \%)$ & $\mathrm{p}=0.636 \ddagger$ \\
\hline Inactivation & $12(42.9 \%)$ & $16(80 \%)$ & $\mathrm{p}=0.010 \dagger$ \\
\hline
\end{tabular}

$12 \dagger$ Pearson chi2 test, $\ddagger$ Fisher's exact test, § Mann-Whitney test 


\section{FIGURES}

Figure 1. Pathological parameters associated with synchronous m-ccRCC
A) Sarcomatoid component, HES x200
B) Diffuse cytoplasmic expression of VEGFA, IHC x200
C) Cytoplasmic and membranous expression of PAR-3, IHC x200
D) PD-L1 overexpression with intense membranous staining, IHC x200

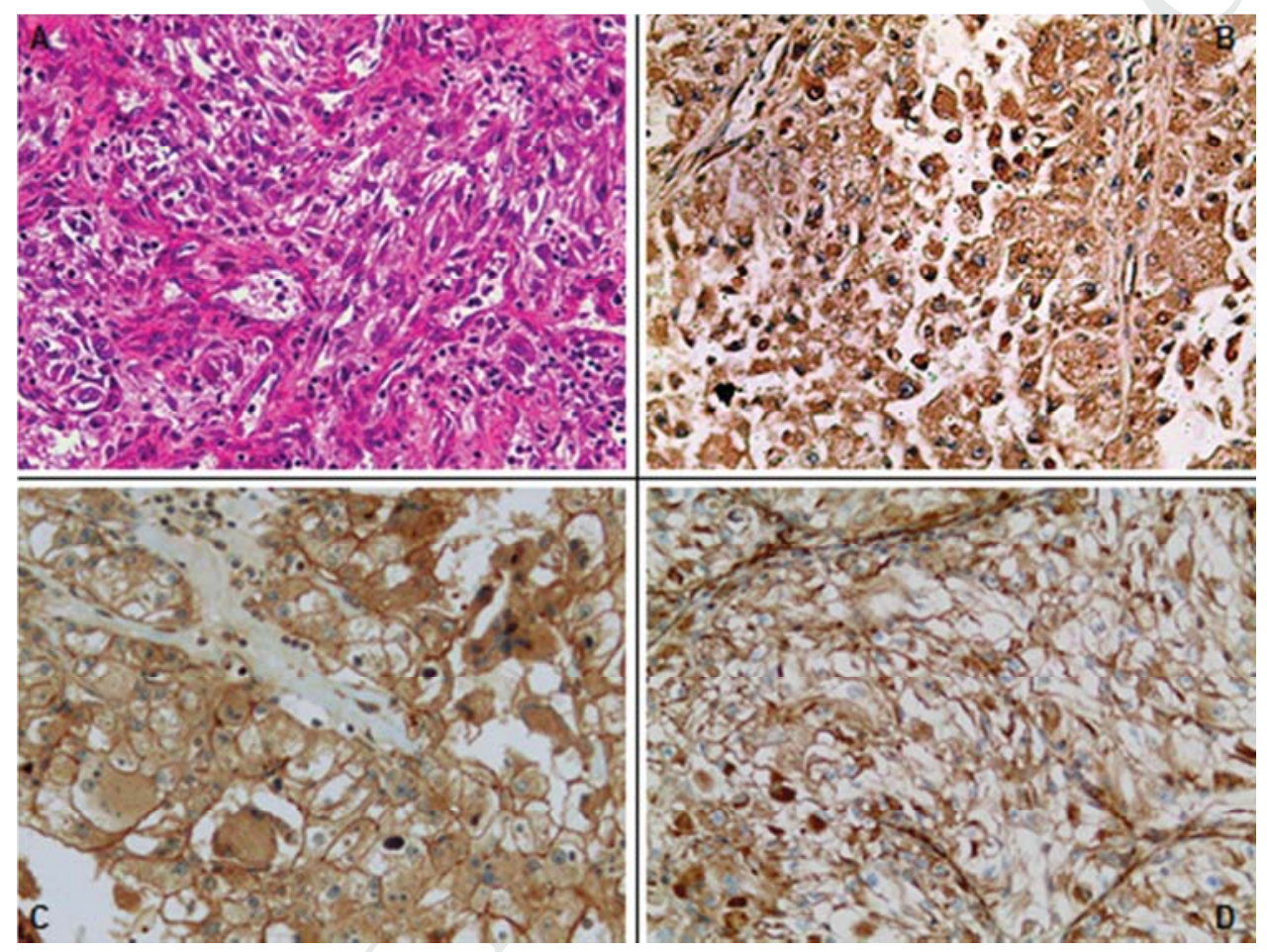


Figure 2. Cancer specific survival in patients from metastasis diagnosis according to metastatic status.

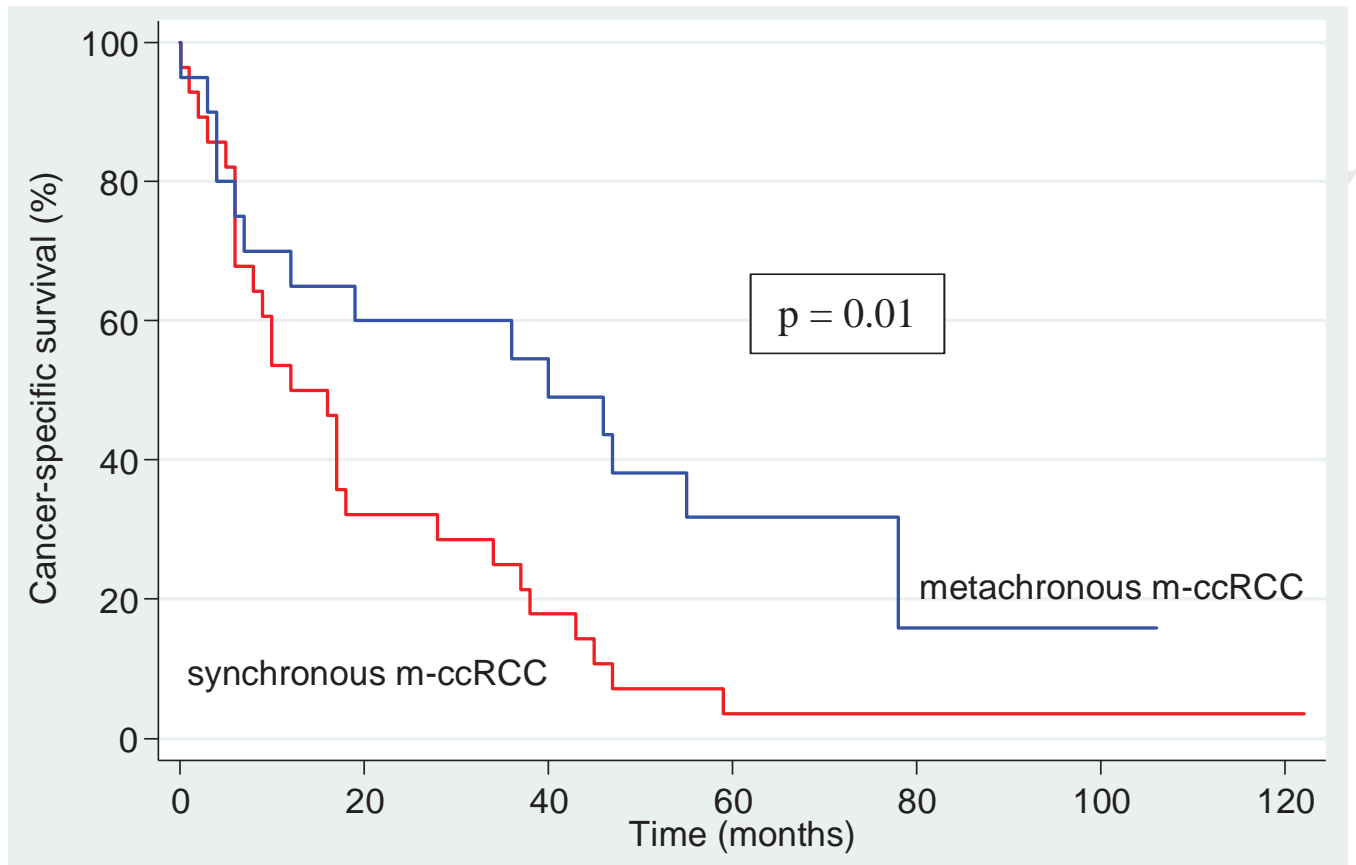

